\title{
Preliminary analyzes in terms of the possibility of reducing energy consumption by the SM42 locomotive used in track works
}

\author{
Pawel Daszkiewicz ${ }^{1, *}$, and Maciej Andrzejewski ${ }^{1}$ \\ ${ }^{1}$ Rail Vehicles Institute TABOR, ul. Warszawska 181, 61-055 Poznan, Poland
}

\begin{abstract}
Track operations require specialized machinery and equipment. Among them, the SM42 locomotive is an indispensable vehicle. Locomotives of this type have a significantly different nature of work compared to locomotives used in passenger and freight traffic. A large percentage share of the work is engine running under idle and under low load. The nature of the load is, among other things, the cause of high fuel consumption. Such a situation calls for a number of necessary technical and organizational activities, leading, inter alia, to reducing energy consumption. The article provides preliminary operational analyzes aimed at identifying the potential for reduce energy consumption by the SM42 locomotive, supporting track works. As a result of reducing the locomotive's downtime with running engine by half, fuel consumption was reduced by approximately $16 \%$.
\end{abstract}

\section{Introduction}

For decades, the primary power source for vehicles used in shunting operations, in most cases for locomotives, were compression ignition (CI) engines of obsolete designs, characterized by high values of effective power and torque, but which often do not meet any emission standards and generate high maintenance costs. Taking into account the vehicles designed for the toughest applications, their engines are further characterized by a large displacement volume, which results in higher fuel consumption and more exhaust gases [1]. It follows, therefore, that the operation of shunting locomotives can cause high energy consumption and substantial emissions, hence the need to pay special attention to issues of reducing their negative environmental impact [2-4].

Performing works within the modernization of railway lines requires the use of specialized machinery and equipment, often equipped with large-volume compression-ignition internal combustion engines with high power outputs. Inevitably, this involves significant fuel consumption and significant emission of harmful pollutants in the exhaust gases $[5,6]$. Negative environmental impacts of activities performed during the construction or modernization of railway infrastructure, further enhances the often very outdated machinery with combustion engines that meet the old and fairly liberal emission standards $[7,8]$.

Therefore, any action that improves the efficiency of track machines in terms of fuel consumption and emission of harmful exhaust gases is valuable [9, 10]. The authors of this paper have made an assessment of the possibilities of improving the operation of these machines. The paper presents an analysis of working conditions and fuel consumption by the SM42 diesel shunting locomotive, which is exactly used for rail works (Fig. 1).

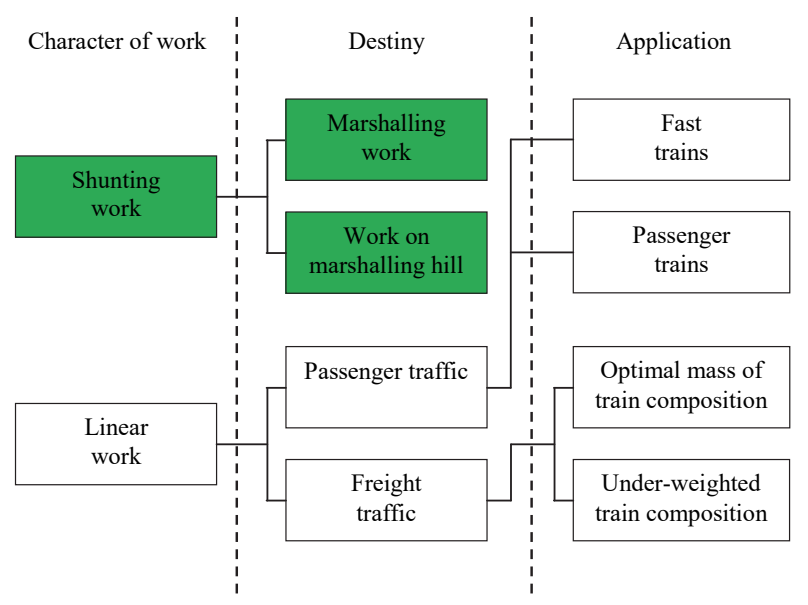

Fig. 1. The basic use of the SM42 diesel shunting locomotive.

It should be noted in the discussed aspects that during operation of diesel locomotives in real conditions, the energy utilization rates of the locomotive are significantly different from those achieved at full power, especially when there is a very high proportion of engine idling. It is also important that in the control system of the locomotive driving system, the control is discrete, determined by the position of the driving adjuster.

* Corresponding author: p.daszkiewicz@tabor.com.pl 


\section{Shunting work}

\subsection{Regulations}

According to railway regulations, based on the Instruction in the techniques of shunting operations (R-34) shunting includes all intended movements of railway vehicles and related operations on railway tracks with the exception of the train entry, exit and transit. Adjusting the train position at the station from one track to another, pushing it into the desired position (reversing, pulling) after previously stopping on the track, should be considered as shunting maneuvers. A shunting locomotive set are locomotives that are coupled with the rail vehicle performing the shunting maneuvers or multiple unit performing shunting operations. The shunting vehicle may be behind, before or between other units. If the station carries out planned shunting maneuvers in coupling, decoupling and remodeling of train sets, as well as the use of station and track sidings associated with it, such stations are usually assigned their own shunting locomotives to carry out these operations [11].

Shunting locomotives generally have one cabin, which can be used for driving in both directions. These vehicles could be with electric drives or combustion engines.

The goals of shunting operations include [12]:

1. moving carts into separate tracks,

2. coupling of cart sets,

3. changing a group of carts in a set,

4. moving carts into position for loading and unloading,

5. bringing and taking back of empty passenger carts onto tracks next to platforms and parking them,

6. moving carts between tracks,

7. picking out selected empty carts with distinct characteristics,

8. moving carts into position for special operations such as: cleaning, washing, decontamination, weighing, repairs, etc. and bringing these cars back onto platforms after they are done,

9. taking carts out of trains sets when they are faulty and would impact the train travel safety.

\subsection{Shunting methods}

The following shunting methods and maneuvers are used [12]:

1) positioning, where the operation (shunting) involves the moving the cart set onto the desired track (place) and the decoupling of any selected carts from the set after it comes to a stop,

2) loose shunting (singular or set), where singular loose shunting means that the shunting locomotive, when pushing a set of carts, stops after reaching the intended speed, which causes the unconnected carts to drift apart and roll onto the desired track; set loose shunting on the other hand involves speeding up of the shunted set after the decoupling of the first connection up to a speed that ensures the shunted set reaches its destination. Then the locomotive stops to allow the decoupled cart set to move away, after which it speeds up again to allow for the detachment of another shunted cart or set,

3) hump shunting, it involves pushing carts off an inclination or a marshalling hill.

Pushing the carts can take place after completion of shunting on the track, or to connect to the cart set in the process of coupling the train. Placement (shunting) can be performed by a: road vehicle, shunter, shifter, or other technical device designed for the movement of rail vehicles [13].

\subsection{Shunting speed}

According to the instructions Ir-9/R34/ shunting maneuvers are performed most frequently on the tracks occupied by the rolling stock, and therefore to be accomplished with the speed needed to maintain the safety of people, vehicles and cargo.

Shunting vehicle speed must not exceed $25 \mathrm{~km} / \mathrm{h}$, with the exception of the following cases $[12,14]$ :

1) $40 \mathrm{~km} / \mathrm{h}$ - when driving a rolling railway vehicle or a train set when the vehicles are pulled on an empty track, of which the driver has been notified; does not apply to driving through crossovers,

2) $20 \mathrm{~km} / \mathrm{h}$ - when moving through unmonitored crossings,

3) $15 \mathrm{~km} / \mathrm{h}$ - when moving a train set forward on a main track at a downward slope of over 2.5 thousandth, and when the shunting vehicle could not be placed on the lower end of the whole set, and when pushing a set towards a marshalling hill when signaled to do so,

4) $10 \mathrm{~km} / \mathrm{h}$ - when performing maneuvers with carts occupied by passengers, with dangerous goods, with the exception of marked labels No. 8 or 15 according to the RID, and tanks marked with an orange strip, for which the speeds are smaller, as well as for carts that exceed gauge or are extremely heavy weighing more than 60 tons, in one set after first notifying the driver by the shunting operations head. Speed does not apply to carts occupied by passengers when the shunting is performed on a secured track $[15,16]$,

5) $5.4 \mathrm{~km} / \mathrm{h}$ - for uncoupled carts coming down from a marshalling hill towards a stationary set at automated stations,

6) $5 \mathrm{~km} / \mathrm{h}$ - if the technical instructions do not specify further speed reduction:

- when pushing carts off of a marshalling hill after the signaling permitted operation "at moderate speed",

- when uncoupling carts with the uncoupling rod,

- when shunting carts loaded with dangerous goods, marked with a warning label No. 8 or 15 according to the RID, and tanks marked with an orange strip,

- when driving the shunting train set forwards when an employee could not take the place in the first pushed cart or vehicle,

- when shunting carts using a road-based vehicle with combustion engine,

7) $3.6 \mathrm{~km} / \mathrm{h}$ - when carts sets pushed off a marshalling hill approach a stationary train set,

8) $3 \mathrm{~km} / \mathrm{h}$ : 
- when the control signal shows "push slowly",

- when approaching a stationary train set with a locomotive or a shunted cart set,

- when shunting carts using mechanical shunting devices.

\section{Research object and conditions of the analysis}

The research object was a vehicle of the NRMM (NonRoad Mobile Machinery) group - mentioned SM42 diesel locomotive (Fig. 2). It is essentially designed for shunting and marshaling works. It can also be used for light freight trains. The main operational parameter for this locomotive is the maximum engine power that is $588 \mathrm{~kW}$ (800 hp).

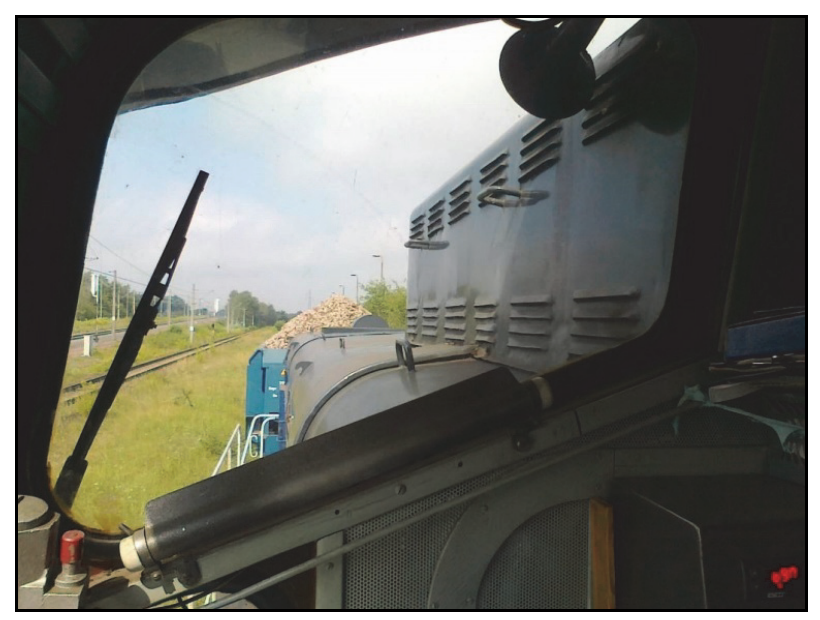

Fig. 2. SM42 locomotive - view from the driver's cab.

For the purpose of the article, the analysis was carried out, among other things, to assess the operating conditions of the SM42 locomotive and the fuel consumption of its engine during track works supporting the modernization of the railway line leading from Poznan to Pila. On this working day, the SM42 locomotive was used to operate five self-unloading wagons, including three "dumpcar" type (with a tipping box) wagons to deliver a new crushed stone to the construction site (Fig. 3 and 4). This crushed stone was loaded onto wagons using a wheel loader.

Detailed works schedule which were made using the SM42 locomotive is presented in Figure 5. Indirectly from the presented information result various ways and conditions of operation of the SM42 locomotive. On the basis of the recorded measurement data, the percentage share of the individual activities performed by the locomotive in the whole cycle of its work (about $4 \mathrm{~h}$ ) was determined (Fig. 6).

An attention is drawn to the large share of activities during which the engine of the SM42 locomotive was idling. Overall it was 155 minutes, which accounted for about $64 \%$ of the total operating time of the locomotive engine (Fig. 7, Tab. 1) [17-19]. In this case, the greatest potential for improving the efficiency of the propulsion system of the locomotive is achieved (achieving greater combustion efficiency). As a result of the various organizational and technical activities, the minimum downtime of the machine with the running engine should be ensured.

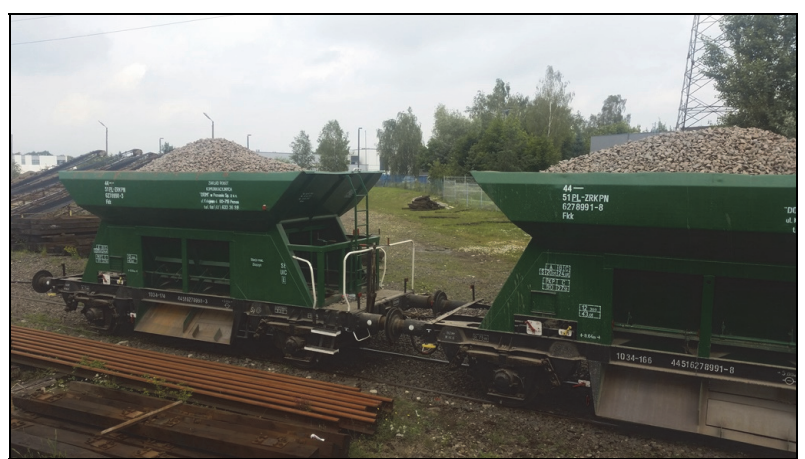

Fig. 3. The part of the train pulled by SM42 locomotive (self-unloading wagons).

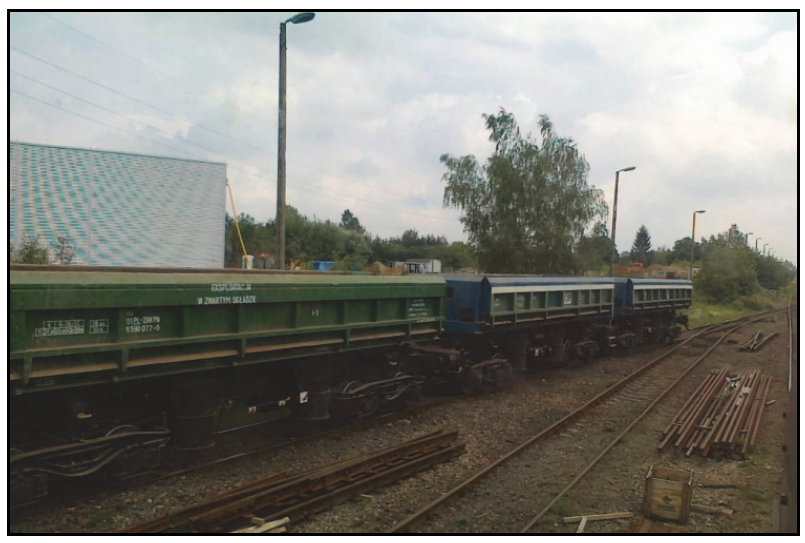

Fig. 4. The part of the train pulled by SM42 locomotive ("dumpcar" type wagons).

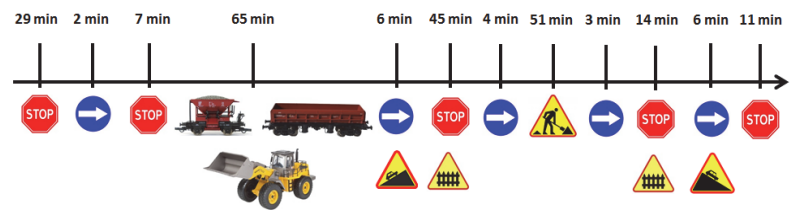

Fig. 5. The way of performing works using the SM42 locomotive.

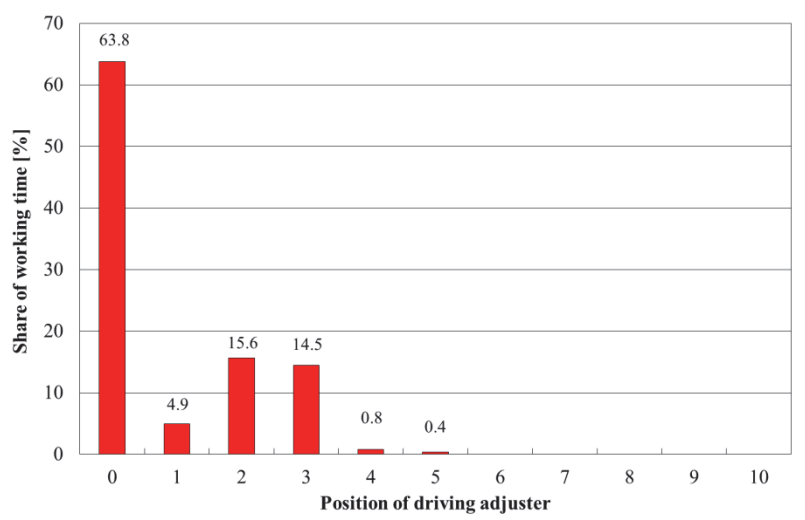

Fig. 6. The histogram of the engine load of the analyzed SM42 locomotive ( $4 \mathrm{~h}$ of work). 


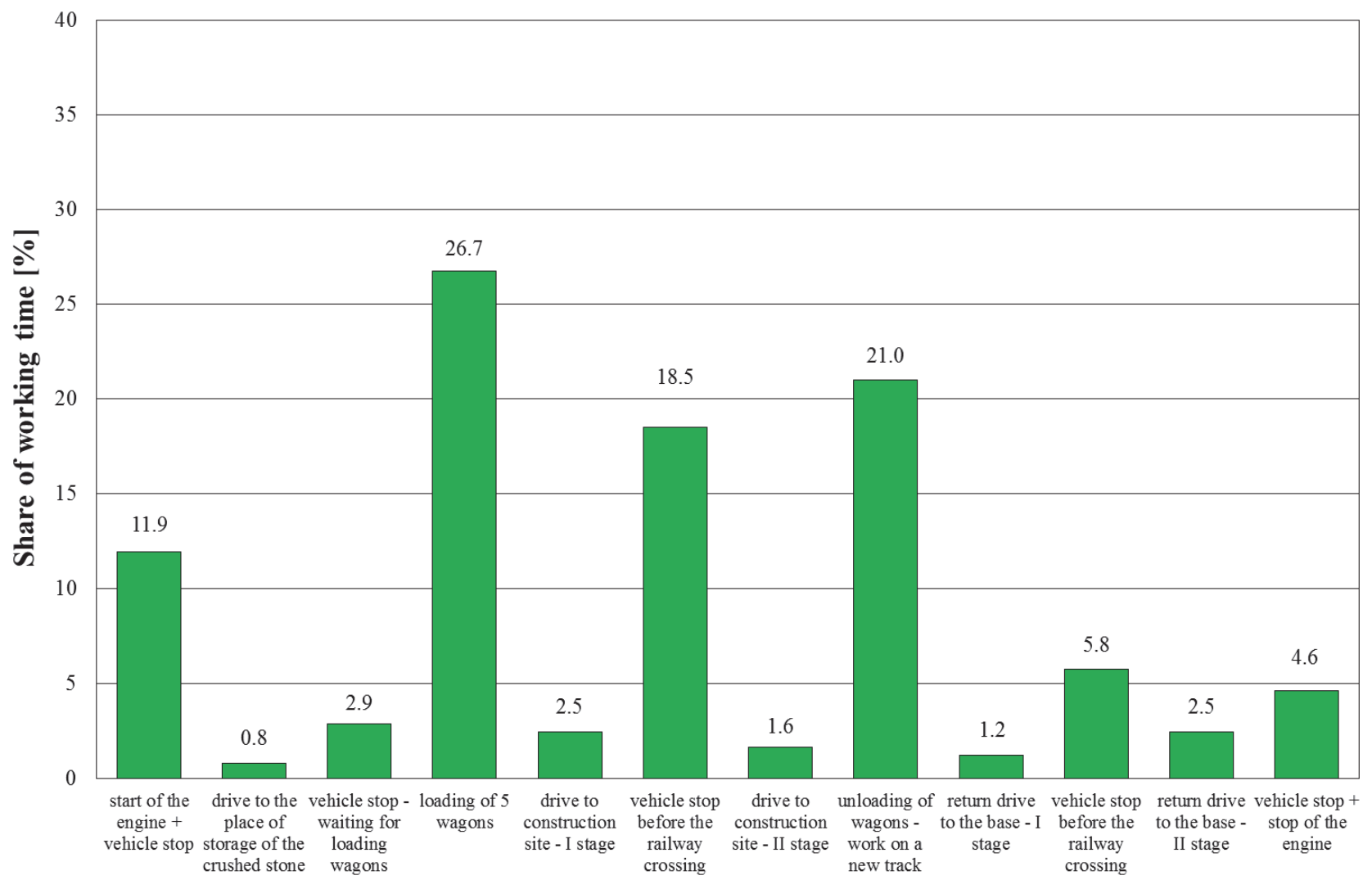

Fig. 7. The share of the individual activities in the whole cycle of work of SM42 locomotive $(4 \mathrm{~h})$.

On the basis of the analyzes, it can be observed that the engine of the locomotive was operating in a narrow range of loads - mainly on the 2 and 3 position of the driving adjuster. Higher positions were used only because of the need to overcome the greater movement resistance while traveling with full wagons under a small hill (occurs on a short segment of the route).

Table 1. The average power of the SM42 locomotive on the individual positions of the driving adjuster.

\begin{tabular}{|c|c|}
\hline $\begin{array}{c}\text { Position of the driving } \\
\text { adjuster }[-]\end{array}$ & $\begin{array}{c}\text { Average usable } \\
\text { power }[\mathrm{kW}]\end{array}$ \\
\hline 1 & 54 \\
\hline 2 & 108 \\
\hline 3 & 162 \\
\hline 4 & 216 \\
\hline 5 & 270 \\
\hline 6 & 324 \\
\hline 7 & 378 \\
\hline 8 & 432 \\
\hline 9 & 486 \\
\hline 10 & 540 \\
\hline
\end{tabular}

\section{Analysis of the possibilities of improving the work efficiency of the SM42 locomotive}

Improving the work efficiency of the SM42 locomotive in terms of reducing energy consumption, the authors looked at the possibility of shortening the duration of some activities carried out within track works (Fig. 5 and
6). In order to estimate fuel savings (as part of improving work organization), it was proposed to reduce engine idling time by $50 \%$. This reduced the work time by 45 minutes, resulting in a reduction in fuel consumption of around $16 \%$ (Fig. 8). It should be noted that data on the amount of fuel used by the locomotive were derived from the electronic fleet management system of the owner of this locomotive. The confirmation of the above effects of the proposed organizational activities is a significant reduction of engine idling time from about $64 \%$ to $55 \%$ - the suggested work cycle (Fig. 9). As could be expected, most contributes to this significant reduction of the first stoppage time of the locomotive before the railway crossing (by more than 20 minutes).

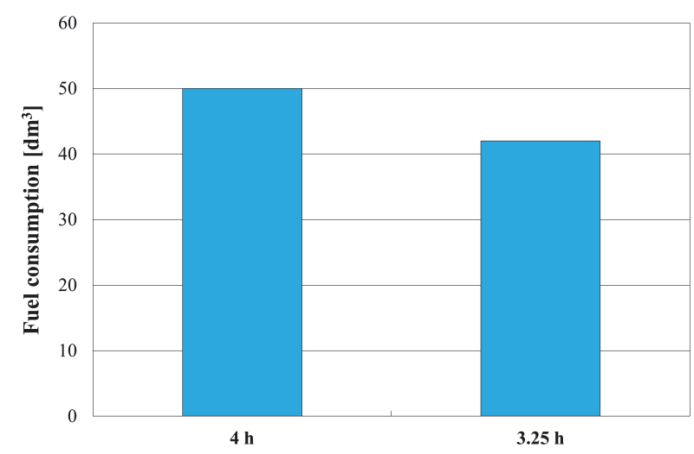

Fig. 8. The amount of fuel consumed by the locomotive engine at the given time of operation.

\footnotetext{
Corresponding author: p.daszkiewicz@tabor.com.pl
} 
This resulted in a decrease in the share of stopping in total activity performed by the locomotive from 18.5 to $11.5 \%$ (Fig. 10).

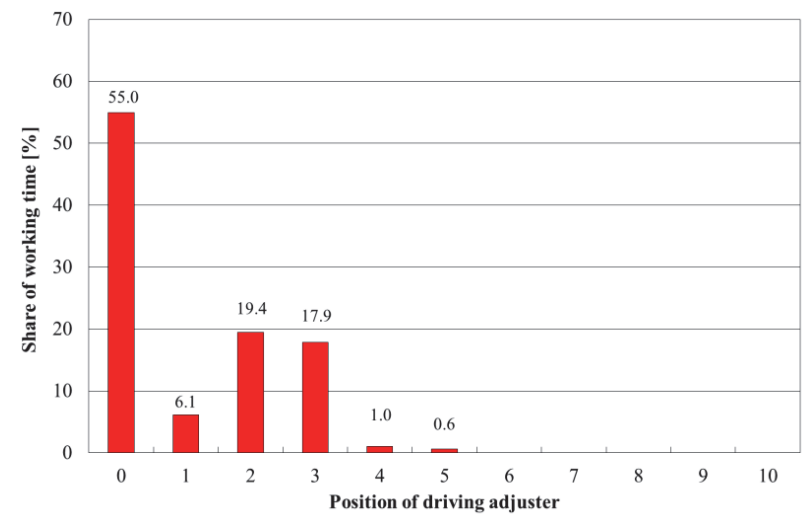

Fig. 9. The histogram of the engine load of the analyzed SM42 locomotive including improved work organization $(3.25 \mathrm{~h}$ of work).

\section{Summary}

Among the initiatives aimed at increasing the efficiency of rail transport, the activities related to reducing the costs of shunting vehicles operation play an important role. The way to achieve this is to modernize diesel locomotives or replace shunting locomotives with more economical rail-road vehicles, additionally taking into account the emission and noise considerations. For decades, the main source of propulsion for vehicles used in shunting works, in most cases locomotives, are diesel engines with obsolete structures, characterized by high efficiency and torque values, which often do not meet emission standards and generate high maintenance costs. If you consider vehicles for the heaviest applications, their propulsion units are also characterized by a high cylinder volume value, which also results in high fuel consumption and high toxic exhaust emission. From the above it follows that the operation of shunting locomotives can cause high energy consumption and significant emission of pollutants, so special attention should be paid to the problem of reducing their negative impact on the environment.

The analyzes were conducted to determine the operating conditions and energy consumption of the SM42 locomotive used during the modernization works on the railway line. There is some energy wastage in track works caused by long and unproductive stoppages of machines with running engines. As a result of the proposed organizational actions, the share of inefficient engine idle time was reduced by almost $9 \%$ (Fig. 7 i 9), resulting in a reduction in fuel consumption of $8 \mathrm{dm}^{3}$ (Fig. 8). In order to further improve the use of chemical energy provided in the fuel, after completing the supplementary tests, an energy balance will be prepared to develop appropriate operating guidelines for operators and users of the SM42 locomotive.

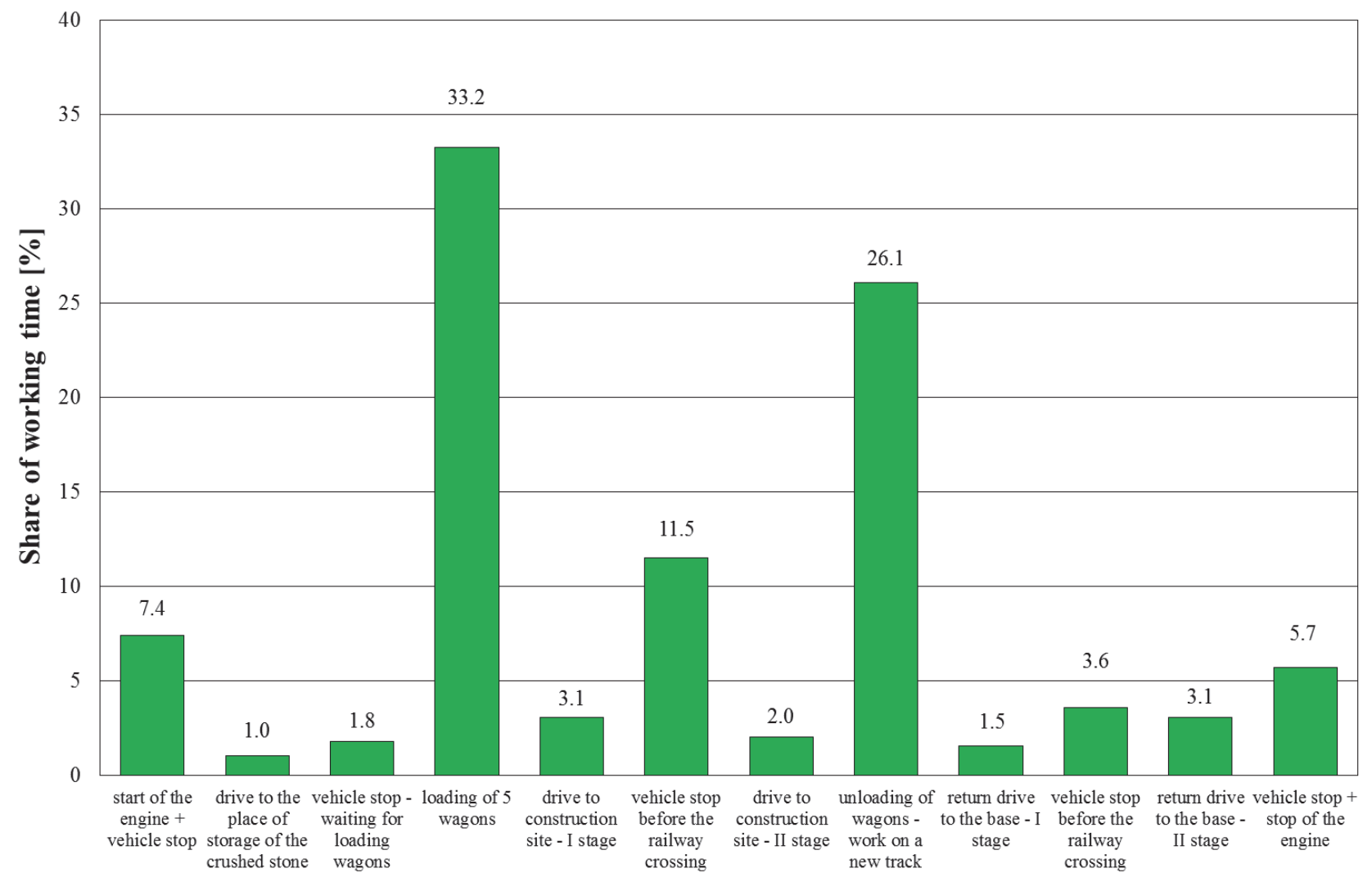

Fig. 10. The share of the individual activities in the whole cycle of work of SM42 locomotive including improved work organization $(3.25 \mathrm{~h})$. 


\section{References}

1. P. Lijewski, J. Merkisz, P. Fuc, A. Ziolkowski, L. Rymaniak, W. Kusiak, European Journal of Forest Research 136, 153-160 (2017), DOI: 10.1007/s10342-016-1015-2

2. P. Fuc, L. Rymaniak, A. Ziolkowski, WIT Transactions on Ecology and the Environment 174, 207-218 (2013), DOI: 10.2495/AIR130181

3. J. Merkisz, M. Bajerlein, W. Kozak, Urban Transport and the Environment in the 21st Century 14, 325 (2008)

4. J. Merkisz, P. Fuc, P. Lijewski, A. Ziolkowski, M. Galant, M. Siedlecki, Journal of Electronic Materials 45, 4028-4037 (2016), DOI: 10.1007/s11664-016-4543-0

5. S. Krezo, O. Mirza, Y. He, S. Kaewunruen, J.M. Sussman, Civil-Comp Press 288, 1-14 (2016)

6. J. Szkopiński, Archives of Transport 29, 65-75 (2014)

7. P. Daszkiewicz, M. Andrzejewski, A. MerkiszGuranowska, H. Stawecka, D. Gallas, Combustion Engines 162, 666-671 (2015)

8. M. Feo-Valero, L. Garci'A-Mene'Ndez, S. Del SazSalazar, Transportation 43, 101-122 (2016)

9. P. Daszkiewicz, M. Andrzejewski, A. MerkiszGuranowska, H. Stawecka, D. Gallas, Combustion Engines 162, 666-671 (2015)

10. M. Feo-Valero, L. Garci'A-Mene'Ndez, S. Del SazSalazar, Transportation 43, 101-122 (2016)

11. J. Merkisz, J. Pielecha, P. Molik, M. Nowak, 2014 IEEE Vehicle Power and Propulsion Conference, Coimbra (2014)

12. Materials of Polish State Railways (PKP)

13. J. Merkisz, P. Lijewski, P. Fuc, S. Weymann, Eksploatacja i Niezawodnosc - Maintenance and Reliability 15, 364-368 (2013)

14. A. Suchecki, J. Nowakowski, T. Knefel, Transport Means - Proceedings of the International Conference 194-197 (2014)

15. J. Merkisz, P. Lijewski, P. Fuc, M. Siedlecki, A. Ziolkowski, IOP Conference Series-Materials Science and Engineering 148, UNSP 012077 (2016), DOI: 10.1088/1757-899X/148/1/012077

16. J. Merkisz, P. Lijewski, P. Fuc, M. Siedlecki, S. Weymann, Applied Engineering in Agriculture 31, 875-879 (2015)

17. J. Markowski, J. Pielecha, R. Jasinski, T. Kniaziewicz, P. Wirkowski, E3S Web of Conferences 10, UNSP 00140 (2016), DOI: $10.1051 / \mathrm{e} 3$ sconf/20161000140

18. J. Merkisz, S. Tarkowski, Eksploatacja i Niezawodnosc - Maintenance and Reliability 2, 5058 (2011)

19. W. Gis, J. Pielecha, J. Waskiewicz, M. Gis, M. Menes, IOP Conference Series-Materials Science and Engineering 148, UNSP 012040 (2016), DOI: $10.1088 / 1757-899 \mathrm{X} / 148 / 1 / 012040$ 